\title{
INTRODUZINDO A INVESTIGAÇÃO NARRATIVA NOS CONTEXTOS DE NOSSAS VIDAS: UMA CONVERSA SOBRE NOSSO TRABALHO COMO INVESTIGADORES NARRATIVOS
}

\author{
DILMA MELLO \\ University Federal de Uberlândia
}

\section{SHAUN MURPHY}

University of Saskatchewan

\section{JEAN CLANDININ \\ University of Alberta}

RESUMO O texto relata nossas experiências como investigadores narrativos, para destacar aspectos que, frequentemente, criam dificuldades para aqueles que se iniciam nesta forma relacional de investigação. Começamos lembrando aos leitores que a investigação narrativa é o estudo da experiência entendida narrativamente. Dessa forma, chamamos a atenção para a investigação narrativa como um fenômeno de estudo e como metodologia de pesquisa. Isso por si só, já cria confusão para aqueles que são novos na investigação narrativa. Destacamos três tensões particulares que, normalmente, causam dificuldades para os pesquisadores. Engajando no início da narrativa autobiográfica, mudando de textos de campo para textos de pesquisa e conduzindo investigações narrativas tornadas propositais para justificativas pessoais, teóricas/práticas e sociais foram as três tensões que selecionamos. Baseando-se em investigações narrativas contínuas e recentemente concluídas, Dilma, Shaun e Jean Clandinin tornaram explícitas as maneiras como mudaram de textos de campo provisórios para textos finais de pesquisa.

Palavras-chave: Investigação narrativa. Experiências de investigação. Conversa sobre pesquisa. Ética relacional.

\section{ABSTRACT INTRODUCING NARRATIVE RESEARCH IN LIFE CONTEXTS: A CONVERSATION ABOUT OUR WORK AS NARRATIVE RESEARCHERS}

The text reports our experiences as narrative researchers to highlight 
aspects of narrative research that often create difficulties for new researchers in this relational form of research. We begin by reminding readers that narrative inquiry is the study of the experience understood in the narrative. Thus, we draw attention to narrative research as a phenomenon under study and methodology for the study. This by itself often creates confusion for those who are new to narrative inquiry. We highlight three particular tensions that often cause difficulties for researchers. Engaging at the beginning of the autobiographical narrative, shifting from field texts to research texts and conducting narrative investigations made purposive for personal, theoretical/practical and social justifications were the three tensions we selected. Drawing on ongoing and recently completed narrative investigations, Dilma, Shaun and Jean have made explicit the ways in which they have moved from interim field texts to final research texts.

Keywords: Narrative investigation. Research experiments. Research Conversation. Relational ethics.

RESUMEN INTRODUCIENDO LA INDAGACIÓN NARRATIVA EM LOS CONTEXOS DE NUESTRAS VIDAS: UNA CONVERSACIÓN SOBRE NUESTRO TRABAJO COMO INVESTIGADORES

\section{NARRATIVOS}

El texto relata nuestras experiencias como investigadores narrativos para destacar aspectos de la investigación narrativa que, frecuentemente, crean dificultades para nuevos investigadores en esta forma relacional de pesquisa. Comenzamos recordando a los lectores que la investigación narrativa es el estudio de la experiencia entendida de forma narrativa. De esta forma, llamamos la atención hacia la investigación narrativa como un fenómeno bajo estudio y como metodología para el estudio. Eso por sí solo, frecuentemente, crea confusión en aquellos que son nuevos en la investigación narrativa. Destacamos tres tensiones particulares que, por lo general, causan dificultades a los investigadores. Comprometiendo en el inicio de la narrativa autobiográfica, transformando los textos de campo en textos de investigación y conduciendo investigaciones narrativas tornadas propuestas de justificaciones personales, teóricas/prácticas y sociales fueron las tres tensiones que seleccionamos. Basándose en investigaciones narrativas continuas e recientemente concluidas, Dilma, Shaun e Jean tornaron explícitas las maneras de cómo transformaron los textos provisorios de campo en textos finales de investigación

Palabras clave: Investigación narrativa. Experiencias de investigación. Conversación sobre investigación. Ética relacional 
Nós três estamos engajados em investigação narrativa há muitos anos. Cada um de nós participou de vários estudos, com professores, jovens, crianças, médicos, estagiários, médicos residentes, administradores, famílias e professores universitários. Aprendemos a trabalhar a partir da seguinte definição de investigação narrativa:

Investigação narrativa é uma maneira de entender a experiência. É uma colaboração entre pesquisador e participantes por um tempo, em um lugar ou série de lugares e na interação social com o meio. Um investigador adota esta matriz como central e continua com o mesmo espírito, concluindo a investigação ainda centrado no viver e contar, revivendo e recontando as histórias das experiências que compõem a vida das pessoas, tanto individual quanto social. (CLANDININ; CONNELLY, 2000, p. 20)

Investigação narrativa é o estudo da experiência entendida narrativamente. Observar cuidadosamente a sua definição nos permite pensar sobre as diferenças de significado de como entendemos a investigação narrativa. Não obstante a característica definidora mais importante da investigação narrativa seja aquela que a define como sendo o estudo da experiência, como ela é vivida e contada, trata-se algo mais do que isso, pois a pesquisa narrativa é mais do que contar histórias, mais do que viver histórias.

A concepção de Dewey (1938: 1997) de experiência dá suporte ao nosso entendimento de investigação narrativa. Trabalhamos a partir da concepção de experiência de Dewey, que a concebe como "um fluxo que muda que é caracterizado por interação contínua do pensamento humano com nosso ambiente pessoal, social e material" (CLANDININ; ROSIEK, 2007, p. 39). Trabalhar com esta concepção de experiência molda o espaço tridimensional da investigação narrativa, segundo as suas dimensões: de temporalidade (passado, presente e futuro), de sociabilidade (com atenção aos eventos pessoais e existenciais que se desenrolam), e de lugar (os espaços geográficos, topológicos, onde os eventos, incluindo os eventos de investigação, acontecem) (CLANDININ; CONNELLY, 2000).

Durante muitos anos, aprendemos bastante, em nossos estudos sobre investigação narrativa, particularmente sobre o que significa viver relacionalmente com os outros, quando nos engajamos em investigação narrativa (CLANDININ; CAINE; STEEVES, 2013) e o que significa viver na fronteira com outras metodologias de pesquisa (CLANDININ; ROSIEK, 2007). Frequentemente, o que aprendemos chama nossa atenção para as tensões com as quais vivemos, enquanto nos engajamos na investigação narrativa.

\section{Vivendo as tensões de engajar-se em investigação narrativa}

o que queremos dizer com tensões é, talvez, não o que normalmente significa tensões, isto é, não vemos tensões como direcionando nossa atenção para um problema a ser resolvido ou algo que possa ser consertado ou mudado, ou suavizado. O que queremos dizer com tensões se baseia no trabalho de Clandinin et al (2010). Enquanto as tensões são frequentemente vistas como tendo "[...] uma valência negativa, isto é, tensões são algo a ser evitado ou suavizado [...]" (2010, p. 82), nós entendemos tensões "[...] em uma maneira mais relacional [...]" (2010, p. 83). Vemos tensões como “[...] vividas entre pessoas, eventos, ou coisas [...] [de maneira que moldam] um espaço entre [...]" (2010, p. 83), um espaço com muito potencial para a investigação. As tensões chamam nossa atenção para os limites da investigação, quando podemos aprender mais por estarmos atentos aos obstáculos, aos lugares onde sentimos a dissonância, a incerteza, a sensação de que algo não está muito certo, ou seja, os luga- 
res que nos fazem perguntar a nós mesmos: 0 que está acontecendo aqui?

Neste artigo, delineamos três tensões que parecem particularmente relevantes para nosso trabalho mais recente: as tensões em torno do início da narrativa autobiográfica, para situar nosso trabalho; as tensões em torno da passagem de textos de campo para textos de pesquisa, e as tensões em torno de justificar cada estudo para responder às justificavas pessoais, práticas e teóricas, que lhes são inerentes. Estas tensões surgem, em parte, das considerações do projeto da investigação narrativa. As considerações do projeto são baseadas em doze medidas de investigação narrativa (CLANDININ; CAINE, 2013). Para tratar as tensões, cada um de nós baseia-se em recentes investigações narrativas com as quais está envolvido.

\section{Situando nossos contextos de pesquisa}

Shaun - Atualmente, estou realizando uma investigação sobre a construção de currículo em uma escola rural, assim intitulada - Vida em uma escola rural: uma investigação narrativa em construção de identidade e construção de currículo na educação rural. Nesta investigação, estou atentando para as experiências de crianças, famílias e professores, no encontro de suas vidas em lugares educacionais rurais. Minha maior dúvida é: como as experiências dentro e fora da escola moldam a construção de currículo e a construção da identidade, para crianças, famílias e professores? Meu interesse surge de minhas próprias experiências, como uma criança rural, e de experiências de trabatho em escolas rurais. Uma tensão que tenho em relação a esta dúvida é o papel de observar o lugar, quando se ensina em escolas rurais.

Jean - Um dos estudos em que eu aprendi muito sobre tensões e sobre ficar acordado, para a minha vida e minha pesquisa, em rela- ção aos participantes, bem como com a área de pesquisa, foi um estudo junto aos jovens que saíram da escola antes de se formarem (CLANDININ; CAINE; STEEVES, 2013). Organizamos o quebra-cabeças da pesquisa em torno das experiências de alunos que abandonam a escola precocemente, incluindo suas histórias sobre o que aquela escola representava em suas histórias de desistência, bem como suas histórias a respeito de abandonar a escola precocemente, isto é, sem um diploma, e de como isso influenciava suas vidas.

Dilma - Meu trabalho atual está relacionado principalmente com a área de ensino para alunos com alguma necessidade especial, especificamente alunos com problemas visuais (cegos e/ou com pouca visão). Estou particularmente interessada na experiência relacional entre professores e alunos, mas também considero o contexto escolar e o meio. Como uma investigadora narrativa, e também como avó de um menino com pouca visão, pensei que seria mais fácil realizar esta investigação e escrever o início da narrativa. No entanto, fiquei surpresa pela tensão pela qual passei, enquanto escrevia o início da minha narrativa.

\section{Tensão 1: Escrevendo o início da narrativa: engajando-se nas investigações narrativas autobiográficas, no início, e em toda a investigação}

Engajar-se na investigação narrativa autobiográfica é muito mais do que participar de qualquer investigação narrativa. Não é fácil trabalhar, mas é importante que comecemos cada investigação narrativa com esta tarefa, como Clandinin (2013, p. 36) a descreveu:

Primeiramente, é importante investigar como você se vê, e se torna, dentro da investigação. Sem ter o entendimento do que traz cada um de nós para nossos quebra-cabeças, nós corre- 
mos o risco de entrar em relacionamentos sem um sentido de quais histórias estamos vivendo e contando nos relacionamentos de pesquisa, e nas maneiras que nós atentamos para as experiências dos participantes da pesquisa.

Observar que determinado trabalho é parte da investigação narrativa não significa que seja um trabalho fácil. O trabalho contínuo, autorreflexivo ou de autoconfrontação, requer que atentemos cuidadosamente para quem somos no mundo e como temos moldado o mundo em que vivemos nossas vidas (CLANDININ; CONNELLY, 2000).

\section{A narrativa inicial de Shaun: uma investigação narrativa na construção do currículo}

Recentemente, Shaun fez uma mudança na sua universidade, a partir do Departamento de Estudos Curriculares para Fundações Educacionais, em meio à tarefa de moldar uma identidade acadêmica, levemente alterada, em relação ao seu novo departamento. Shaun não tinha nenhuma intenção de abandonar suas raízes na teoria curricular. Ele tinha sido um professor de matemática, mas não estava mais ensinando essa disciplina. Ele sempre teve interesse na educação do professor rural e reconhecer este interesse parecia certo para ele. Tinha sido criado em uma área rural, ensinou em escolas rurais e estava muito interessado na educação rural, para crianças, jovens e professores. Shaun estava envolvido em duas investigações narrativas anteriores, que moldaram como ele se engajaria nesta pesquisa. Uma investigação mais antiga desenvolveu-se quando ele integrava uma equipe de pesquisa (CLANDININ; HUBER; HUBER; MURPHY; MURRAY -ORR; PEARCE; STEEVES, 2006), investigando as experiências de crianças, professores e administradores, em uma escola elementar urbana. Sua investigação mais recente focava as experiências de crianças, famílias e professores
(CLANDININ; HUBER; MURPHY; MURRAY-ORR, 2010), em uma era de realização de testes. Estas duas investigações moldaram seu pensamento sobre como o currículo é composto de relacionamentos. No estudo posterior, nós (HUBER; MURPHY; CLANDININ, 2011) desenvolvemos a ideia de construção de currículo familiar, para reconhecer os mundos de construção de currículo de crianças e famílias. Em sua nova investigação, Shaun estava interessado nas maneiras como as famílias, crianças, professores e administradores moldam as experiências de construção de currículo (CLANDININ; CONNELLY, 1992), atento às áreas rurais. Esta investigação foi moldada em relação a currículo baseado no lugar (AJAYI, 2014; AZANO, 2011; 2014; BROOK, 2013; GRUENEWALD; SMITH, 2014; WAITE, 2013).

\section{Um início de narrativa}

Nasci em uma cidade pequena e fui criado em uma fazenda. Meus pais tiveram carreiras profissionais em nossa pequena cidade. Sempre senti que vivia em dois mundos. Eu não era realmente uma criança de fazenda, apesar de aquela ser uma fazenda de trabalho, e eu não era realmente uma criança da cidade, embora estivéssemos muito envolvidos nas atividades da cidade. Eu pegava o ônibus para a escola, todos os dias, brincava e fazia tarefas na fazenda, toda tarde, e todos os finais de semana. Brincava nas florestas, nos campos e no lamaçal, na estrada. Eu sabia que estava destinado a ir para a universidade, para uma vida longe da fazenda. Quando me tornei professor, comecei minha carreira em outra cidade pequena. Trabalhei em lugares diferentes e passei o período de tempo mais longo em uma escola no campo, sem nenhuma cidade por perto. Quando me tornei um professor, continuei com meu interesse em ensinar em áreas rurais, mas não foquei nesse aspecto. Quando fui convidado a trabalhar com crianças, professores, famí- 
lias e administradores, em uma cidade pequena, rapidamente aceitei. Ainda estou tentando descobrir o que significa ensinar em escolas rurais. Ainda estou tentando descobrir o que o rural realmente significa nas vidas das pessoas. Imagino como a atenção para com a educação baseada no lugar pode apoiar a aprendizagem de crianças e o ensino de professores.

\section{Dúvidas sobre o início da minha narrativa}

Minha experiência como um menino de fazen$\mathrm{da}$, vivendo em dois mundos, molda quem eu sou, em minha investigação atual. Sei que o meu interesse neste trabalho vem da minha origem em uma fazenda perto de uma cidadezinha, na parte norte rural de Alberta (uma província no Canadá). Sei que o meu interesse na educação rural vem da minha infância, a carreira de ensino em escolas rurais, o trabatho de pesquisa sobre os mundos das crianças, e meus pensamentos sobre a construção do currículo. Quando escrevo artigos, estou ciente de que isso me molda e, enquanto eu não escrevo, em um artigo, o início de uma narrativa, frequentemente, acho que isso é entremeado em todo o artigo de maneira que eu espero mostrar ao leitor que estou conectado com o trabalho, além de apenas demonstrar interesse acadêmico. Em um curso recente, notei, na escrita de meus alunos, que eles acham que "tendência" é algo ruim, mas tendência é um termo neutro e está sempre presente no nosso trabalho. É algo para prestar a atenção e vale a pena notar que eu tenho uma inclinação pessoal em relação à educação rural.

\section{A narrativa inicial de Jean: investigação narrativa sobre a saída precoce da escola}

Quando Jean se envolveu, na pesquisa narrativa, com alunos que deixam a escola precoce- mente, ela tinha sido moldada por vários estudos, bem como por suas experiências como criança, na escola, como professora e conseIheira, nas escolas, e por seu trabalho como formadora de professores. As dúvidas que se desenvolveram, a partir do trabalho anterior moldaram o estudo dos alunos que abandonaram a escola cedo. Nós (CLANDININ; HUBER; HUBER; MURPHY; MURRAY-ORR; PEARCE; STEEVES, 2006) tínhamos completado uma investigação narrativa, em uma escola, junto com crianças, professores e administradores escolares. Nós também tínhamos tido conversas com alguns pais e membros de família. Embora o foco fosse sobre as maneiras pelas quais as identidades dos professores e das crianças se entrelaçam nas escolas, ficamos cientes de que algumas crianças tinham começado a se desengajar das escolas, já no nível primário. No último capítulo do nosso livro, nos baseamos no estudo de Smyth et al (2004), de desistentes da escola, e começamos a imaginar a experiência de jovens que deixaram a escola antes de se formar. As dúvidas, moldadas no estudo com crianças e professores, na Escola Elementar Ravine, permaneceram, e começamos a desenhar um novo estudo, uma investigação narrativa em que aprendemos através das experiências e das histórias dos jovens que abandonaram a escola, antes de se formar.

Fomos lembrados da importância de investigar as nossas próprias histórias de escola, histórias que moldaram nossas suposições, entendimentos e experiências, dentro e fora da escola. Isso foi importante para nós, uma vez que nos ajudou a reconhecer as razões para nos envolvermos neste trabalho, que crescia de nossas experiências, dentro e fora da escola. Enquanto havia múltiplos pontos iniciais para a pesquisa, tais como investigações narrativas anteriores, as agências de financiamento da pesquisa e os requisitos éticos da universidade, cada investigador nar- 
rativo começou com uma investigação narrativa autobiográfica para nos ajudar a entender mais profundamente quem cada um de nós era, na pesquisa, e o que nos atraiu para a pesquisa. Começamos nossas investigações narrativas autobiográficas em relação a quem cada um de nós era na pesquisa. Nossos propósitos eram menos sobre contar nossas próprias histórias, de maneira abrangente, e mais sobre o modo como entramos nos relacionamentos de investigação; quem nós éramos e estávamos nos tornando em relação aos jovens que abandonaram a escola cedo, bem como com quem estávamos e no que estávamos nos tornando, em relação às histórias de escola.

No que se segue, compartilho segmentos da representação de uma imagem de palavra de alguns inícios da minha narrativa moldada em quatro seções temporais: área inicial/ áreas anteriores, formatura do ensino médio, tornando-se um professor e tornando-se um investigador narrativo. Compartilho um segmento de cada seção:

\section{I. Áreas anteriores.}

As tensões e contradições

vividas a cada dia, cada semana, cada mês.

Deixando um mundo

Entrando em outro mundo.

Cada dia

Cada semana

Cada ano.

\section{Formatura do Ensino Médio.}

Nenhuma história de graduação na família Histórias de formar uma vida como esposa de um fazendeiro

casamento, filhos

uma vida em uma fazenda

trabalho duro,

não ter coisas suficientes, muito trabalho

os padrões intergeracionais.

III. Tornando-se um professor.

Tornando-se um professor

Professores pertencem a escolas.

Deixando um mundo

Entrando em outro.
Vivendo sempre as memórias incorporadas De viverem dois mundos

A cada dia, cada semana, cada ano.

IV. Tornando-se um investigador narrativo.

Complexidades

vividas com o passar do tempo

vividas em múltiplos lugares

em múltiplos relacionamentos

do que significa conhecer múltiplos mundos

de crianças e famílias

que são vistas como outros,

cujas histórias não se adaptam

a enredos dominantes. (CLANDININ; CAINE; STEEVES, 2013, p. 7-10)

Estas histórias não eram fáceis para eu escrever nem fáceis de serem compartilhadas com outros. Para facilitar, chamo a atenção que eram histórias que eu ainda não tinha escrito antes e eram histórias que eu não tinha disponibilizado para a investigação narrativa. Enquanto falava com eles, eu já tinha falado deles para mim mesmo, citando-os em novos estudos. Eu não as tornei públicas, exceto em lugares seguros, em áreas de conhecimento profissionais (CLANDININ; CONNELLY, 1995); lugares onde eu poderia me tornar vulnerável, para aprender a partir das tensões que eu estava vivenciando. Ao escrevê-las e investigá-las narrativamente, elas permitiam que eu me posicionasse no estudo maior das experiências de jovens que abandonaram a escola cedo, bem como me posicionasse em relação aos dois jovens participantes, com quem convivi no estudo.

\section{A narrativa inicial de Dilma: ensinando e vivendo em relação com pessoas com necessidades especiais}

Logo que Dilma decidiu realizar uma investigação sobre as experiências de ensinar alunos com problemas de visão, ela achava que os inícios de sua narrativa poderiam estar rela- 
cionados com a sua própria prática, como professora, que ela tinha de ser em relação aos alunos com problemas de visão. Lembrou-se de uma criança que ela tinha ensinado, há alguns anos antes, enquanto trabalhava para uma faculdade pequena. Imaginando que era sua primeira experiência em relação a pessoas com necessidades especiais, Dilma tentou o início de uma narrativa.

Há alguns anos, como professora, planejei minha aula pensando nos meus alunos, esperando que eles aprendessem facilmente. Preparei slides com palavras, em cores diferentes: verbos em preto, adjetivos em vermelho, substantivos em amarelo, cognatos em azul, e assim por diante. Todo mundo parecia estar tão atento e satisfeito, mas, depois que a aula acabou, um menino veio até mim e me disse que ele não conseguia entender as diferenças com base nas cores. Ele era daltônico. E apesar das minhas preocupações em relação à inclusão, reconheci que eu estava muito distante de estar ciente de algumas diferenças.

Logo que Dilma terminou parte da sua primeira tentativa de início da narrativa, ela compartilhou esta parte com alguns outros professores, que também estavam trabalhando com o início da narrativa. Enquanto lia sua história para o grupo, ela logo percebeu que aquela experiência não tinha sido sua primeira experiência em relação a pessoas com necessidades especiais, e lembrou-se de outra situação que tinha vivido, quando era uma universitária. Ela finalmente descobriu que tinha achado a sua história inicial e que sua história de aluna universitária a ajudaria a discutir como e quando despertou para as diferenças.

Quando estava voltando para casa, da Universidade, eu me deparei com uma garota no ônibus. Ela era surda e não conseguia falar usando sua voz, como fazemos. Eu não sei por que razão ela decidiu "falar" comigo. Ela me tocou e insistiu em ter uma conversa. Eu a ignorei, porque eu não conseguia usar aquela linguagem. Logo percebi que era eu a desafiada naquela situação. Daquele momento em diante, decidi que eu construiria pontes de linguagem. Minha ideia era que eu precisava ser capaz de usar diferentes maneiras de comunicar.

Novamente, Dilma percebeu que não era a primeira situação em que ela tinha estado em relação com pessoas diferentes, e lembrou-se de outra experiência: seu irmão ficou cego por um ano, durante a infância, no Brasil. Ela se perguntou como poderia não estar ciente, em relação ao quebra-cabeça de pesquisa, daquela parte da sua história de família, relacionada à diferença. Dessa vez, (re)começou o início de suas narrativas com a experiência que teve da experiência de seu irmão.

Meu irmão ficou cego por um ano, quando eu tinha cerca de cinco anos, e ele tinha sete. Não entendi a razão por que isso aconteceu, mas eu costumava ajuda-lo a ir à escola. No entanto, algumas vezes, eu era malvada e fazia piadas sobre sua situação. Lembro-me de uma vez, quando o guiei até um muro, em frente à nossa casa. Nós dois rimos, e logo eu o levei para casa. Provavelmente, como criança, eu estava tentando investigar esta nova situação. Estava tentando entender o que era, e não conseguia fazer sentido disso. Também me perguntava qual era o meu papel, naquela experiência, como irmã de um menino cego. Naquela época, me disseram que ele precisava de vitamina $A$, e ele tinha que comer muitas cenouras, todos os dias, para que pudesse enxergar novamente. Finalmente, depois de um longo ano, sua visão retornou. Esta foi minha primeira experiência com cegueira.

De início, minhas narrativas acabaram sendo escritas, ao mesmo tempo, porque minhas três tentativas iniciais criaram uma oportunidade para eu perceber que minhas experiências relacionais com pessoas com neces- 
sidades especiais eram muito mais intensas, e frequentes, na minha vida, do que eu tinha percebido. Tinha planejado apontar para a minha falta de conhecimento sobre contextos educacionais inclusivos, mas percebi que eu sabia muito menos do que imaginei; achava que sabia muito mais. Minhas tentativas de inícios narrativos me mostraram quão cega eu era em minha "relação" com pessoas com necessidades especiais, embora veja agora a frequência dos meus relacionamentos. Só acordei realmente para o ensino de alunos diferentes, quando meu neto nasceu com visão congênita baixa. Minha atenção para a diferença do aluno está principalmente baseada nestas três experiências.

\section{Tensão 2: Tensões de mudar de textos de campo para textos de pesquisa}

\section{Shaun}

$\mathrm{Na}$ investigação narrativa de Shaun, a respeito da construção do currículo, em uma escola rural, ele começou com uma dúvida aberta sobre o que as crianças, famílias, professores, membros da comunidade e administradores podem vivenciar, na construção de seu currículo escolar. Ele queria que a investigação fosse moldada, em parte, pelos interesses das pessoas na escola. Embora tivesse clareza sobre o aspecto da pesquisa de construção de currículo, estava feliz de deixar a escola moldar o possivel foco da pesquisa. 0 que surgiu foi um interesse em jardinagem escolar. Shaun começou com conversas com o administrador, fez anotações de campo sobre experiências nas classes de 50 e 6 음 anos, enquanto eles aprendiam sobre jardinagem, fez um passeio a um complexo de idosos, com as crianças, e o professor ajudou a construir o espaço real do jardim, conversou com as famílias (pais e avós), teve conversas com as crianças, coletou artefatos das crian- ças e dos professores e tirou fotografias, em todo o processo. Os textos de campo compostos começaram a moldar os textos de pesquisa. Os formatos iniciais dos textos de pesquisa eram uma proposta para uma conferência e um artigo para posterior publicação. Shaun foi ensinado por Jean, que conferências nunca são um ponto final para artigos, mas um lugar para refinar a escrita e buscar o insumo de outros. Um outro aspecto importante da escrita de textos de pesquisa é o envolvimento dos participantes. A escrita foi compartilhada com várias pessoas envolvidas na pesquisa e suas dúvidas moldaram mais textos. Foi importante, enquanto os textos de pesquisa eram escritos, pensar sobre os textos de campo, como uma maneira de representar a experiência, e de como eram investigados através do espaço de investigação narrativa tridimensional (CLANDININ; CONNELLY, 2000). Esse espaço é ligado pelos aspectos comuns da narrativa: de sociabilidade, de temporalidade e de lugar (CONNELLY; CLANDININ, 2006), e uma atenção para dentro, para fora, para trás e para a frente, à experiência da pesquisa e do pesquisador. Clandinin e Connelly (2000) explicaram estas quatro direções:

[...] para dentro, queremos dizer em relação a condições internas, tais como sentimentos, esperanças, reações estéticas e disposições morais. Para fora, queremos dizer em relação a condições existenciais, isto é, o meio. Para trás e para a frente, nos referimos à temporalidade - passado, presente e futuro. $(2000$, p. 50$)$

\section{Jean}

$\mathrm{Na}$ investigação narrativa com alunos que abandonam a escola cedo, nos engajamos em mudanças interpretativas diferentes, de textos de campo para textos de pesquisa. A primeira mudança envolvia trabalhar dentro do espaço da investigação narrativa tridimensional, de temporalidade, de sociabilidade e de lugar, com os textos de campo, para cada partici- 
pante. Nós colocamos para a frente as linhas narrativas, aqueles enredos narrativos que discernimos sobre a vida de qual participante poderia ser contada. Entrelaçamos aquelas linhas narrativas em um texto de pesquisa provisório, que chamávamos de relato narrativo (CLANDININ; CONNELLY, 2000). Baseamo-nos nos textos de campo (transcrições, notas de campo, artefatos), e trabalhamos dentro do espaço de investigação narrativa tridimensional, enquanto escrevíamos esses relatos.

Estávamos conscientes de que eram as histórias dos participantes, compartilhadas em relação a nós, que estavam sendo escritas nos relatos narrativos. Já que a investigação narrativa é relacional, sabíamos que estávamos compondo os relatos narrativos junto com os participantes. Enquanto alguns participantes estavam mais envolvidos nos processos de mudar de textos de campo para os textos de pesquisa, nós negociamos cada relato narrativo junto a cada participante, com apenas uma exceção. Um jovem tinha indicado que ele queria que sua história fosse contada, mas nós não conseguimos contatá-lo, para negociar o relato narrativo. Nós pedimos a cada participante para selecionar um pseudônimo para eles mesmos. Nos relatos narrativos, descrevemos comunidades do lar e informação demográfica, quando era importante para as experiências dos participantes. Não demos nomes às cidades grandes, pequenas, ou escolas, para garantir o anonimato dos participantes. Ocasionalmente, quando mencionamos escolas e lugares, criamos pseudônimos para eles.

Quando mudamos de textos de campo para escrever os textos de pesquisa provisórios, isto é, os relatos narrativos, formamos grupos de trabalho contínuos, o que nos permitiu responder às interpretações, uns dos outros, nos relatos narrativos. Em todo texto, permanecemos respeitosos, no que concerne às vidas dos participantes. Tínhamos consciência de que nossa intenção não era dissecar vidas, mas, ao invés disso, oferecer uma representação de narrativas de experiência.

Nosso segundo movimento interpretativo envolvia examinar os dezenove relatos narrativos, para discernir linhas narrativas que pareceriam ecoar em todos os relatos. Com o objetivo de preparar um texto de pesquisa final, para a agência financiadora, trabalhamos, colaborativamente, como uma equipe de 11 membros, para examinar os 19 relatos narrativos, e destacamos seis tópicos ressonantes ou padrões que discernimos, enquanto examinávamos os relatos narrativos dos alunos que abandonaram a escola prematuramente.

\section{Dilma}

Junto com meu participante de pesquisa, decidimos contar e recontar suas próprias experiências, na escola, e nossas conversas em que estávamos tentando resolver como poderia a educação inclusiva ser entendida, considerando a perspectiva de uma pessoa com necessidades especiais. Juntos, nós tentamos compor o significado das experiências vividas, tendo em mente particularmente os movimentos, para dentro e para fora, relacionados à investigação narrativa, como proposta por Clandinin e Connelly (2000).

Primeiro de tudo, conversamos, e meu participante compartilhou experiências vividas na escola, com professores e colegas de classe. Fiz o papel de tutora, responsável por criar um lugar seguro para o participante compartilhar suas experiências, e também responsável por atender alguns dos requisitos da escola, e tentar falar com os professores sobre as preocupações do meu participante, tendo em mente suas experiências vividas e compartilhadas em nossas seções de conversa. Segundo, escrevemos algumas narrativas e enquanto as compusemos, como textos de campo, o participante escolheu um pseudônimo para ele mesmo e, 
como pesquisadora, honrei a escolha. Ele também compôs narrativas diferentes, usando fotos, que ele tinha tirado na escola, e alguns poemas que ele tinha escrito sobre a sua experiência na sala de aula. Finalmente, eu transformei os textos de campo em textos de pesquisa, escrevendo alguns relatos narrativos sobre as experiências vividas e compartilhadas. Nós dois passamos a entender as histórias dos meus participantes, junto com aquelas da escola, em relação a quem ele era, como aluno, e quais eram suas necessidades. Aquelas foram algumas das linhas que eu consegui compor, em relação ao participante, enquanto prestando atenção ao contexto escolar e nas duas perspectivas sobre Educação Inclusiva.

\section{Tensão 3: tensões para justificar nossas investigações narrativas, de maneira pessoal, prática e social}

Escrevemos em outro texto sobre a necessidade de imaginar o fim da investigação e como responderemos a questões de 'e daí?' e 'quem se importa?' - questões que todos os pesquisadores precisam responder (CLANDININ; CONNELLY, 2000; CLANDININ, 2013). Enquanto, normalmente, estas questões são feitas no final de um estudo de pesquisa, na investigação narrativa, foi no início de nossas investigações narrativas que nós primeiro encontramos as questões de: "e daí e quem se importa" questões que nos levaram em direção à necessidade de justificar nossas investigações narrativas, de três maneiras: as justificativas pessoais, práticas e sociais/teóricas. Em parte, o trabalho de investigação narrativa autobiográfica e de atenção especial à literatura acadêmica são maneiras de começar a responder a estas questões.

Considerações de justificativa pessoal nos levam a entender mais profundamente por que a investigação importa para cada um de nós. "Nossos interesses na pesquisa vêm de nossas próprias narrativas de experiência e moldam nossos enredos de investigação narrativa" (CLANDININ; CONNELLY, 2000, p. 121). Como notamos na seção intitulada Tensão 1, nós sabemos quão dificil é engajar-se na investigação narrativa autobiográfica e entender a complexidade de compreender quem somos na investigação e, ao fazer isso, passar a entender nossos propósitos e justificativas para o engajamento na investigação. Enquanto não podemos nos engajar na investigação narrativa, sem considerações sobre quem somos e estamos nos tornando, na investigação, e o que nos traz para a investigação, justificativas pessoais de cada investigação narrativa não são suficientes.

Considerações de justificativas práticas também são importantes, já que pensamos sobre como nosso trabalho será assumido por outros, no ensino, na enfermagem, na elaboração de políticas, na educação do professor, e assim por diante. Quando escrevemos sobre nossos estudos, nos textos de pesquisa finais, perguntas de como nós justificamos nosso trabalho praticamente são particularmente importantes. Isso também é, frequentemente, um empreendimento dificil.

Considerações sobre justificativas pessoais e práticas são frequentemente consideradas não importantes para a literatura acadêmica. Como Clandinin e Connelly (2000) escreveram:

[...] embora encorajemos a justificativa de interesse na investigação em termos pessoais, as normas de investigação consideram que as pessoas devem somente justificar a investigação em termos sociais [...] Nós precisamos estar preparados para escrever 'eu', enquanto fazemos a transição de textos de campo para textos de pesquisa. Quando escrevemos 'eu', precisamos transmitir um sentido de significância social. $(2000$, p. 122) 
No entanto, notamos que é crucial que todos os três tipos de justificativa estejam em evidência, nas investigações narrativas, até mesmo se as justificativas pessoais são algumas vezes não totalmente evidentes, em textos de pesquisa públicos.

\section{Shaun: justificando a investigação narrativa na educação rural}

Considerando as justificativas que tenho para esta pesquisa, vejo como e quem eu sou, quem eu serei e como eu quero ser, em relação à educação do professor que é moldada pelo meu interesse na educação rural.

\section{Justificativas pessoais}

Sei que a construção de um currículo atento ao lugar é importante nas vidas das crianças, famílias e professores. Este entendimento surge da minha própria experiência em construir currículos com crianças. Espera-se que escolas rurais sigam um currículo provinciano obrigatório/guia de disciplinas. A aprendizagem que está situada nos lugares das vidas das crianças e professores é a aprendizagem que reconhece como somos moldados pelos lugares onde vivemos.

\section{Justificativas práticas}

Esta investigação narrativa diz respeito especificamente às vidas de crianças, famílias e professores da escola rural, e se constrói nas investigações de narrativas passadas, nas vidas na escola, na construção de currículo, na construção da identidade e em transições da vida. Esta pesquisa será de longo prazo e atende, por sua vez, a contextos específicos, tais como experiências familiares, em escolas e em casas, a construção da identidade e do currículo das crianças e dos professores, e o trabalho de administradores em uma pequena escola rural. Da mesma forma que nossos participantes estão sempre no meio de suas vidas, como no desfile contínuo da experiência, as investigações narrativas também estão. Situado em relação a investigações narrativas anteriores, estas também moldam investigações narrativas futuras. Tanto a pesquisa quanto a metodologia são moldadas pela nossa pesquisa.

\section{Justificativas sociais/teóricas}

Baseei-me nos conceitos de experiência de Dewey (1938: 1997) e nos currículos comuns de Schwab (1978) de aprendiz, professor, matéria e meio, enquanto moldava esta nova investigação. O conceito de construção de currículo, de Connelly e Clandinin (1988), ocorrendo na intersecção de professor, aprendiz, matéria e meio, moldou mais meu pensamento. Junto com professores, por muitos anos, Clandinin e Connelly estudaram estas intersecções, gradualmente, desenvolvendo as construções narrativas de conhecimento dos professores como "conhecimento prático pessoal" (CONNELLY; CLANDININ, 1988), os contextos dos professores como "áreas de conhecimento profissionais" (CLANDININ; CONNELLY, 1995), e as identidades dos professores como "histórias de vida" (CONNELLY; CLANDININ, 1999).

A investigação atual é moldada entendendo-se que um currículo de vidas é concebido como uma contranarrativa, frente a narrativas dominantes, sociais, culturais, institucionais e linguísticas, moldando as vidas nas escolas. Ao invés de ver o currículo como somente matérias obrigatórias; as identidades dos professores e das crianças, suas histórias de vida, compostas em salas de aula e escolas, são centrais na negociação de um currículo de vidas (CLANDININ ET AL, 2006). Uma reconceitualização de construção de currículo posterior implicava na conceitualização de "construção de currículo familiar", como uma maneira de entender as interações das crianças e famílias, enquanto elas compunham suas vidas, em casa e em lugares comunitários (HUBER ET AL, 2011). Esta 
reconceitualização de construção de currículo mostrou, posteriormente, que as crianças e suas famílias vivenciaram muitas tensões, enquanto elas viajavam para, de, dentro e entre os mundos de construção do currículo familiar e do currículo escolar. Empregando estes entendimentos na minha investigação atual, me ajudará a considerar como isso pode ser entendido em relação à educação, atenta à construção do currículo com base no lugar.

\section{Jean: justificando a investigação} narrativa com alunos que abandonaram a escola cedo

À medida que justifico a investigação narrativa das experiências de alunos que abandonaram a escola cedo, percebo que tenho sido moldada pelas experiências de participar na investigação junto com os jovens. Quem eu sou agora, e quem eu estou me tornando, isto é, minhas histórias de vida têm mudado através da investigação narrativa com as pessoas jovens que saíram da escola antes da formatura.

\section{Justificativas pessoais}

À medida em que me aprofundava em minhas experiências, tornei visivel meu conhecimento de dois mundos, o mundo da escola e o mundo de casa. Baseei-me no trabalho de Lugones (1987), ao falar de mundos. Viver em dois mundos tão diferentes tornou as tensões e contradições visíveis para mim, desde cedo, na minha vida. Movendo-me entre os meus mundos, de casa e da escola, eu tornei visivel que, para mim, o mundo da escola era um lugar de doença, para aqueles que não se ajustavam, que não pertenciam facilmente às escolas onde os ambientes são diferenciados, não somente por graus e desempenho, mas também por acesso a vestimenta, comida e bens materiais. Encontrar o sucesso definido nas narrativas escolares dominantes não foi um privilégio, nas minhas narrativas familiares, no meu mundo de casa. Terminar o segundo grau foi uma escolha, não uma expectativa. Minhas histórias de vida eram compostas entre mundos, valorizando tanto o mundo da casa quanto o da escola, escolhendo ensinar, mas sempre sabendo que as crianças e as famílias viviam nos dois mundos, que os mundos que cada pessoa habitava poderia ser moldado por enredos radicalmente diferentes (CLANDININ; CAINE; STEEVES, 2013).

\section{Justificativas práticas}

Despertando para o fato de quão restritas são as narrativas para alguns jovens e quão dificil é para alguns viverem circunscritos às histórias dominantes da escola é parte de como justifico a investigação narrativa com os alunos que a abandonaram precocemente. Comecei a ver que era dificil, para muitos, até mesmo perceber ou imaginar as complexidades das vidas dos jovens e dos mundos em que eles viviam. Passei a entender a importância de prestar atenção em como o olhar de dentro das histórias de escola, muito frequentemente, torna invisivel as vidas de jovens e famílias, cujas histórias não se enquadram nos ambientes dominantes. Ao me envolver na investigação narrativa junto com os jovens que abandonaram a escola cedo, eu passei a ver a importância de reconhecer e prestar atenção às experiências dos jovens que lutam para ser reconhecidos e vistos.

\section{Justificativas sociais/teóricas}

Clandinin, Caine e Steeves (2013) escreveram, em outro texto, sobre as justificativas sociais e teóricas do trabalho com alunos que abandonaram a escola cedo.

Nós passamos a entender muito sobre a necessidade de prestar atenção a transições. Ficamos perturbados por pontos de vista comuns de transição e como estas noções fo- 
cam nossa atenção nas escolas, nas políticas e procedimentos que afetam a juventude. Focar no evento de transição obscurece nossa visão de jovem vivendo nas e das transições. Os entendimentos narrativos das histórias de vida sempre em movimento, abertas para movimentação e mudança, levou-nos a reconsiderar a composição da vida de jovens que abandonaram a escola cedo, uma transição fora da escola. Prestando atenção cuidadosamente nas vidas dos jovens, nosso entendimento mudou de maneira coerente com uma conceitualização narrativa de transição. Passamos a entender de maneira mais complexa como histórias de vida são moldadas por, e moldadas em momentos incorporados de transição.

Ao atentarmos para a vida dos jovens à medida que eles ficavam visíveis nas histórias contadas sobre eles, nós atentávamos para o que eles sabiam e para os contextos ou áreas de conhecimento nas quais eles tinham vivido dentro e fora das escolas. Como as áreas de conhecimento institucional ofereciam a eles cada vez menos possibilidades para continuar a compor as identidades de suas vidas, as suas histórias de vida, não ficaram paralisados. Eles se basearam no conhecimento que tinham de si mesmos, que foi formado durante anos, e em outros múltiplos contextos e relacionamentos, para mudar suas histórias de vida. Acordando para seguir em outras direções que moldaram suas áreas de conhecimento, eles improvisaram maneiras de fazer com que suas vidas fizessem sentido. Algumas vezes, eles escolheram mudar de escola ou sair da escola por um curto espaço de tempo, ou trocar alguns relacionamentos por outros. Eles fizeram essas mudanças atentos a sempre buscar maneiras de fazer sentido com as suas histórias de vida, que ligavam seus conhecimentos e seus contextos de história. Ligados dentro das múltiplas áreas de história, os jovens nos mostraram como eles improvisaram algo novo, que permitia que fossem em frente, para continuar a composição da vida dentro das escolas, tentando fazer a escola funcionar para eles até que a única maneira de alcançar a coerência narrativa fosse sair da escola. (CLANDININ; CAINE; STEEVES, 2013, p. 327)
Dilma: justificando investigações com experiências de alunos com necessidades especiais

\section{Justificativas pessoais}

Como indicado na primeira parte deste artigo, comecei meu trabalho atual dando atenção para a área de educação inclusiva, junto a alunos com necessidades especiais, focando nas pessoas que tinham pouca visão. No entanto, quando comecei a escrever minhas histórias iniciais, ficou claro para mim que, como professor, eu precisava começar comigo mesmo e minhas próprias experiências, junto com os meus alunos e membros da família. Então, meu neto nasceu com visão congênita baixa, causada por degeneração macular e, mais tarde, eu fiquei com pouca visão. Minha experiência de vida mudou completamente a maneira como eu concebia a educação inclusiva. Por razões pessoais, precisei e senti que tinha que realizar estudos sobre a Educação Inclusiva, considerando a perspectiva daqueles frequentemente excluídos. Depois de passar por muitas experiências dificeis, com meu neto, na escola, e comigo mesma, no trabalho, decidi que estava na hora de trazer minhas experiências para a minha vida profissional, como uma investigadora narrativa, afinal, vida e educação é um caminho que vai e vem e se aprende considerando os dois aspectos, como sugerido por Dewey (1938: 1997).

\section{Justificativas práticas}

Minha justificativa prática está muito relacionada a minha justificativa pessoal. Não poderia, sozinha, ser uma investigadora narrativa que realiza investigações sobre educação inclusiva, sem considerar tensões relacionadas à área de ensino, como uma educadora de professores. Estava e ainda estou desejosa de tentar entender este caminho e criar condições para meus alunos graduados, e ainda os 
que estão na graduação, meus colegas na Universidade com quem eu trabalho, para ficarem cientes desse mundo de diferenças. Escolas e alunos de todos os niveis merecem ensino diferente, atendendo a diversidade.

Há também tantas famílias no Brasil, meu país natal, tentando entender seus filhos com deficiência para poder ajudá-los. Gostaria de saber se meu trabalho de educação, como professora, poderia ser de alguma ajuda para eles. Crianças vão para a escola e todas merecem aprender. Tento ajudar professores na graduação, e já formados, para saber se há muitas perspectivas diferentes de ser entendido e de entender educação e vida.

\section{Justificativa social}

Uma vez mais vejo como minha justificativa social está bem interconectada a minhas justificativas pessoais e práticas. Pensamento acadêmico é geralmente conduzido através de lentes objetivas e, como resultado, uma investigação autobiográfica ou uma investigação, em que alguém tem um parente como participante, pode algumas vezes ser mal-entendida ou não muito bem considerada. Murphy, Huber e Clandinin (2012) compartilham e discutem seu ponto de vista sobre currículo, atendendo aos dois mundos de construção de currículo. Eles entendem que o currículo é feito e vivido em contextos familiares e de casa, e uma outra construção de currículo é construída e vivida na escola. Os autores notam que é importante prestar atenção ao que acontece entre os dois mundos e o movimento e a negociação para crianças, enquanto elas viajam entre estes dois mundos. Frequentando estes dois mundos, como um investigador narrativo, eu justifico minha pesquisa socialmente, considerando que existem muitas investigações realizadas a respeito de currículo, na escola, mas não muitas atentas à construção de currículo vivido em casa, entre os membros da família.
Além disso, situo minha justificativa social e a necessidade de investigar a educação inclusiva, levando em consideração o trabatho de Lugones (1987), considerando a viagem pelo mundo e as percepções que moldam como nós entendemos e vemos aqueles mundos. Lugones (1987) escreveu que há duas percepções que podem chamar nossa atenção para mundos diferentes, a percepção arrogante e a amorosa. A Educação Inclusiva tem sido principalmente investigada olhando para o desafio da posição e perspectiva de um estranho. Eu estava e ainda estou interessada em tentar estar ciente e entender outras perspectivas possíveis.

Finalmente, planejarei e realizarei minha investigação tentando entender maneiras diferentes de pertencer à sala de aula, enquanto lidando com as diferenças, segundo minha leitura de Wenger (1998), que propõe que a sala de aula pode ser vivida como uma comunidade de aprendizagem e prática, significando que a aprendizagem é uma experiência vivida, negociada nos ambientes escolares (CLANDININ; CONNELLY, 1995).

Antes de nos dirigirmos aos pensamentos de conclusão, queremos enfatizar a importância de nossas responsabilidades éticas, em uma investigação narrativa. Estas responsabilidades são um dos aspectos mais salientes de nossa pesquisa, e moldam nossas investigações do início ao fim.

\section{Responsabilidades éticas: a}

\section{ética relacional de engajar-se na investigação narrativa}

Embora não discutido em seções anteriores desse trabalho, há um sentido em nossa consideração inicial, nas narrativas, a mudança de textos de campo para textos de pesquisa e as justificativas que moldam uma investigação da centralidade do relacionamento en- 
tre os participantes e o pesquisador. Temos mostrado como nossas investigações surgem de nossa experiência em relação com os outros, como nossos textos de campo moldam os textos de pesquisa, em relação aos participantes, e como nossas justificativas são situadas em relação com a metodologia, o trabalho teórico e, o mais importante, as pessoas. "O relacionamento é a chave do que os investigadores narrativos fazem" (CLANDININ; CONNELLY, 2000, p. 189).

A importância da relação cria uma resposta ética, que vai além do processo ético que precisamos engajar, em nossas universidades, e atende as obrigações que temos com as pessoas com quem nós trabalhamos em uma investigação. Questões éticas são centrais ao longo da investigação narrativa e enquanto estas podem mudar e movimentar "nunca estão longe de nossas investigações, não importa onde estamos no processo de investigação" (CLANDININ; CONNELLY, 2000, p. 170). Connelly e Clandinin (1988) escreveram sobre a negociação contínua das narrativas de experiências realizadas entre pesquisadores e participantes envolvidos na investigação, a "negociação das unidades narrativas de duas pessoas" (1988, p. 281). Para eles, "este foi um processo experiencial profundo que vive no centro dos relacionamentos em que o pesquisador e o participante negociam. Dessa forma, as narrativas de suas experiências moldam a investigação" (CLANDININ; CAINE; STEEVES, 2013, p. 64). Obrigações éticas é o aspecto que mais pressiona uma investigação narrativa.

\section{Concluindo pensamentos}

Iniciamos este trabalho com a intenção de usar nossas experiências como investigadores narrativos para destacar aspectos da investigação narrativa que frequentemente criam dificuldades para aqueles novos investigadores nesta forma relacional de pesquisa. Começa- mos lembrando aos leitores que a investigação narrativa é o estudo da experiência entendida narrativamente. Dessa forma, chamamos a atenção para a investigação narrativa, como um fenômeno sob estudo e metodologia para o estudo. Isso, por si só, já cria confusão para aqueles que se iniciam na investigação narrativa. Nós também quisemos destacar que há múltiplas tensões em engajar-se na investigação narrativa. Destacamos três tensões particulares que, normalmente, causam dificuldades para os pesquisadores. Engajando no início da narrativa autobiográfica, mudando de textos de campo para textos de pesquisa, e conduzindo investigações narrativas tornadas propositais para justificativas pessoais, teóricas/práticas e sociais.

Os inícios narrativos são fundamentais para se engajar na investigação narrativa, e as experiências que moldam investigações narrativas diferentes, de cada pessoa, precisam ser empreendidas em cada nova investigação narrativa. Como Dilma ilustrou, há muitas experiências nas quais podemos nos basear para escrever nossos inícios narrativos, em uma investigação; ela demonstrou, de forma competente, a complexidade de situar seu trabalho em relação a suas experiências, no desenvolvimento de sua vida. Escreveu a respeito de muitas experiências que moldaram sua maneira de pensar sobre a investigação narrativa na inclusão educacional. Enquanto considerava porque estava interessada e quais entendimentos ela trouxe para a sua investigação narrativa, ela continuou no seu trabalho como professora, suas interações em lugares públicos, suas conexões familiares, e sua experiência pessoal sobre a questão da pouca visão. Jean trouxe um entendimento da complexidade de suas experiências, enquanto compunha suas histórias de vida, enquanto ela vivia os mundos da escola e da casa, e enquanto se movia entre estes dois mundos. Shaun narrou sua expe- 
riência, como menino vivendo em uma área rural, e suas experiências de ensino, em sua carreira, que moldaram um interesse profundo na educação rural.

Pesquisadores iniciantes em investigação narrativa passam seguidamente por tensões enquanto lutam para entender o movimento de estar no campo, para compor textos de campo, e compor textos provisórios e textos finais de pesquisa (CLANDININ; CONNELLY, 2000). Baseando-se em investigações narrativas contínuas e recentemente completadas, Shaun, Dilma e Jean tornaram explícitas as maneiras como eles mudaram de textos de campo provisórios para textos finais de pesquisa.

O terceiro conjunto de tensões envolveu a necessidade de justificar as investigações narrativas, justificativas que são moldadas por questões de significado e significância social. Estas justificativas convocam investigadores narrativos para perceber as maneiras como seus estudos contribuem para maiores conversas e diálogos, na pesquisa de ciência social. Novamente, baseando-se nas experiências de Dilma, Shaun e Jean, nós destacamos como justificamos as investigações narrativas em estudos recentes.

O pessoal está situado em relação aos inícios narrativos do pesquisador e tornados mais claros na abertura de tais processos de pesquisas. Dessa maneira, mostramos, como investigadores narrativos, o que trazemos para esta pesquisa e como nos posicionamos para empreender nossas investigações. Na justificativa pessoal, investigamos a respeito de nosso próprio conhecimento e consideramos como este conhecimento nos ajuda na investigação. Frequentemente, é uma maneira de localizar nossa paixão para o tópico em estudo.

Uma justificativa prática, normalmente, nos aproxima das experiências de outros e dos contextos sociais em que eles estão posicionados. Amiúde, fazemos perguntas sobre ensino, cuidado ou práticas sociais. Como parte da justificativa prática, os investigadores narrativos consideram questões de justiça social e equidade. Nós imaginamos, junto com os participantes, como suas e nossas experiências podem ser moldadas de maneiras diferentes no futuro (CLANDININ; CAINE, 2013, p. 174).

É na justificativa prática que o social "e daí" começa a tomar forma. Consideramos a dimensão social da experiência e, dessa maneira, contribuímos para os contextos sociais. A justificativa teórica/social junta estas duas preocupações. Ao fazê-lo, percebemos que o social informa o teórico e o teórico informa o social. Nesta justificativa, consideramos como nossa pesquisa molda a metodologia. Que novas revelações trazemos para a investigação narrativa? Como a metodologia é colocada em primeiro lugar? Dessa maneira, nossas investigações ajudam as pessoas a entender as experiências de outros. Nós contribuímos para o conhecimento de nossas disciplinas (ensino, medicina, trabalho social, línguas etc.) e conversas políticas.

Evidenciamos, no texto, que as três justificativas estão intimamente conectadas. Não obstante tenha sido possivel descrevê-las, separadamente, entendemos que essas são dimensões justapostas.

Conseguimos destrinchar três linhas para investigadores narrativos considerarem que é evidente que, ao interligar nosso trabalho, estamos levando em conta quem somos, o que investigamos e por que conduzimos investigações narrativas. No centro de uma investigação narrativa está a experiência, tanto a nossa, pessoal, e a dos participantes, quanto a experiência em si de conduzir uma investigação narrativa. 


\section{Referências}

AJAYI, L. Investigating effective teaching methods for a place-based teacher preparation in a rural community. Educational Research for Policy and Practice, 13 (3), p. 251-268, 2014.

AZANO, A. The possibility of place: One teacher's use of place-based instruction for English students in a rural high school. Journal of Research in Rural Education, 26 (10), p. 26-10, 2011.

AZANO, A.). Rural: The Other Neglected" R": Making Space for Place in School Libraries. Knowledge Quest, 43 (1), p. 60, 2014.

BROOK, J. Placing elementary music education: a case study of a Canadian rural music program. Music Education Research, 15 (3), p. 290-303, 2013.

CLANDININ, D. J. Engaging in narrative inquiry. Walnut Creek, CA: Left Coast Press, Inc, 2013.

CLANDININ, D. J.; CONNELLY, F. M. Narrative inquiry: experience and story in qualitative research. San Francisco, CA: Jossey-Bass, 2000.

CLANDININ, D. J.; CONNELLY, F. M. Teacher's professional knowledge landscapes. New York: Teachers College Press, 1995.

CLANDININ, D. J.; CONNELLY, F. M. Teacher as curriculum maker. In: JACKSON, P. W. (Ed.). Handbook of research on curriculum. New York: Macmillan, 1992. p. 363-401.

CLANDININ, D. J.; CAINE, V. Narrative inquiry. In: TRAINOR, A. A.; GRAUE, E. (Eds.). Reviewing qualitative research in the social sciences. London: Routledge, 2013. p. 166-179.

CLANDININ, D. J.; CAINE, V.; STEEVES, P. Composing lives in transition. London: Emerald Press, 2013.

CLANDININ, D. J.; HUBER, J.; MURPHY, M. S.; MURRAY -ORR, A. Negotiating narrative inquiries: living in a tension-filled midst. The Journal of Educational Research, 103, p. 81-90, 2010.

CLANDININ, D. J.; HUBER, J.; HUBER, M.; MURPHY, M. S.; MURRAY-ORR, A.; PEARCE, M.; STEEVES, P. Composing diverse identities: narrative inquiries into the interwoven lives of children and teachers. London: Routledge, 2006.

CLANDININ, D. J.; ROSIEK, J. Mapping a landscape of narrative inquiry: borderland spaces and tensions. In: CLANDININ, D. J. (Ed.). Handbook of narrative inquiry: mapping methodology. Thousand Oaks, CA: Sage Publications, 2007. p. 35-75.

CONNELLY, F. M.; CLANDININ, D. J. Narrative inquiry. In: GREEN, J.; CAMILLI, G.; ELMORE, P. (Eds.). Handbook of complementary methods in education research. Mahwah, NJ: Lawrence Erlbaum, 2006. p. 477-487.

CONNELLY, F. M.; CLANDININ, D. J. Shaping a professional identity: stories of educational practice. New York: Teachers College Press, 1999.

CONNELLY, F. M.; CLANDININ, D. J. Teachers as curriculum planners: narratives of experience. New York, NY: Teachers College Press, 1988.

DEWEY, J. Experience and education. New York: Simon and Schuster Inc, 1938.

DEWEY, J. Experience and education. New York: Touchstone [1938], 1997.

GRUENEWALD, D. A.; SMITH, G. A. Place-based education in the global age: local diversity. London: Routledge, 2014.

HUBER, J.; MURPHY, M. S.; CLANDININ, D. J. Places of curriculum making: narrative inquiries into children's lives in motion. New York: Emerald Group Pub Limited., 2011.

LUGONES, M. Playfulness, world traveling and loving perceptions. Hypatia, 2 (2), p. 3-19, 1987.

MURPHY, M. S.; HUBER, J.; CLANDININ, D. J. Narrative inquiry into two worlds of curriculum making. Learning Landscapes, 5, p. 219-236, 2012.

SCHWAB, J. J. The practical: tTranslation into curriculum. In: WESTBURY, I.; WILKOF, N. J. (Eds.). Science, curriculum, and liberal education: Selected essays. Chicago: University of Chicago Press, 1978. p. 365383. 
SMYTH, J.; HATTAM, R.; WITH CANNON, J.; EDWARDS, J.; WILSON, N.; WURST, S. Dropping out, drifting off, being excluded: becoming somebody without school. New York: Peter Lang Publishing, 2004.

WAITE, S. 'Knowing your place in the world': how place and culture support and obstruct educational aims.
Cambridge Journal of Education, 43 (4), p. 413-433, 2013.

WENGER, E. Communities of practcies: learning, meaning and identity. Cambridge University Press, 1998.

Recebido em: 30.03.2016

Aprovado em: 01.11.2016

Dilma Mello é mestre em Linguística Aplicada e Estudos da Linguagem, pela Pontifícia Universidade Católica de São Paulo, e Doutora em Linguística Aplicada e Estudos da Linguagem, pela Pontifícia Universidade Católica de São Paulo, com passagem pela Universidade de Alberta-Canadá, para a realização de doutorado sanduíche, com bolsa CAPES (2003-2004), e para Pós-doutoramento, com bolsa CAPES (2012-2013). Atualmente, é professora Associado II da Universidade Federal de Uberlândia e líder do GPNEP (Grupo de Pesquisa Narrativa e Educação de Professores). e-mail: $\underline{\text { mello. }}$ dilma@gmail.com.

Universidade Federal de Uberlândia, Instituto de Letras e Linguística. Av. João Naves de Ávila, 2121 bl U sala 1 U206 Santa Mônica. Uberlândia, MG, Brasil, CEP: 38408-100.

Shaun Murphy, PhD, is an Associate Professor in Curriculum Studies at the University of Saskatchewan. He was a primary schoolteacher for 20 years. Shaun co-authored Composing Diverse Identities: Narrative Inquiries into the Interwoven Lives of Children and Teachers (Routledge, 2006) and Places of Curriculum Making: Children's Lives in Motion (Emerald, 2011). His current research interests are in mathematics education, curriculum, familial curriculum making, and teacher and student identity. Email: shaun.murphy@usask.ca

Universidade de Saskatchewan - Saskatoon, SK S7N 5C5, Canadá.

D. Jean Clandinin is Professor and Director of the Centre for Research for Teacher Education and Development at the University of Alberta. She is a former teacher, counselor, and psychologist. She co-authored with F. Michael Connelly four books and many chapters and articles. Their most recent book is Narrative Inquiry: Experience and Story in Qualitative Research. Jean also coauthored Composing Diverse Identities: Narrative Inquiries into the Interwoven Lives of Children and Teachers (Routledge, 2006) and Places of Curriculum Making: Children's Lives in Motion (Emerald, 2011). Jean is currently working on a narrative inquiry with youth and families of Aboriginal heritage as well as on a narrative inquiry with teachers who leave teaching within the first five years of teaching. She is past Vice President of Division B of AERA and is the 1993 winner of AERA's Early Career Award. She is the 1999 winner of the Canadian Education Association Whitworth Award for educational research. She was awarded the Division B Lifetime Achievement Award in 2002 from AERA. She is a 2001 winner of the Kaplan Research Achievement Award, the University of Alberta's highest award for research and a 2004 Killam Scholar at the University of Alberta. Email: jean.clandinin@ualberta.ca

Universidade de Alberta -116 St \& 85 Ave, Edmonton, AB T6G 2R3, Canadá. 